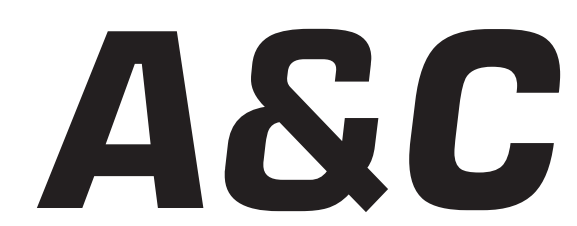

Revista de Direito Administrativo \& Constitucional

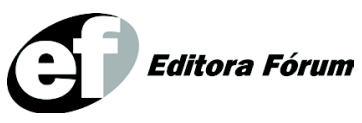

A\&C R. de Dir. Administrativo e Constitucional, Belo Horizonte, ano 6, n. 24, p. 1-246, abr.jun. 2006 


\section{A\&C REVISTA DE DIREITO ADMINISTRATIVO E CONSTITUCIONAL}

\section{IPDA}

Instituto Paranaense

de Direito Administrativo

Direção Geral

Romeu Felipe Bacellar Filho

Direção Editorial

Paulo Roberto Ferreira Motta

Direção Executiva

Emerson Gabardo

Conselho de Redação

Edgar Chiuratto Guimarães

Adriana da Costa Ricardo Schier

Célio Heitor Guimarães

Conselho Editorial

Adilson Abreu Dallari

Alice Gonzáles Borges

Carlos Ari Sundfeld

Carlos Ayres Britto

Carlos Delpiazzo

Cármen Lúcia Antunes Rocha

Celso Antônio Bandeira de Mello

Clèmerson Merlin Clève

Clóvis Beznos

Enrique Silva Cimma

Eros Roberto Grau

Fabrício Motta

Guilhermo Andrés Muñoz (in memoriam)

Jaime Rodríguez-Arana Muñoz

Jorge Luís Salomoni
José Carlos Abraão

José Eduardo Martins Cardoso

José Luís Said

José Mario Serrate Paz

Juan Pablo Cajarville Peruffo

Juarez Freitas

Julio Rodolfo Comadira

Luís Enrique Chase Plate

Lúcia Valle Figueiredo

Manoel de Oliveira Franco Sobrinho

(in memoriam)

Marçal Justen Filho

Marcelo Figueiredo

Márcio Cammarosano

Maria Cristina Cesar de Oliveira
Nelson Figueiredo

Odilon Borges Junior

Pascual Caiella

Paulo Eduardo Garrido Modesto

Paulo Henrique Blasi

Paulo Neves de Carvalho (in memoriam)

Paulo Ricardo Schier

Pedro Paulo de Almeida Dutra

Regina Maria Macedo Nery Ferrari

Rogério Gesta Leal

Rolando Pantoja Bauzá

Sérgio Ferraz

Valmir Pontes Filho

Yara Stropa

Weida Zancaner

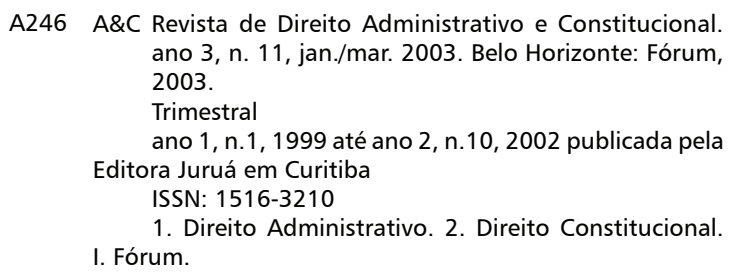

A246 A\&C Revista de Direito Administrativo e Constitucional. ano 3, n. 11, jan./mar. 2003. Belo Horizonte: Fórum, 2003.

Trimestral

ano 1, n.1, 1999 até ano 2, n.10, 2002 publicada pela Editora Juruá em Curitiba

ISSN: 1516-3210

1. Direito Administrativo. 2. Direito Constitucional. I. Fórum.

CDD: 342 CDU: 33.342

(c) Editora Fórum Ltda. 2006

Todos os direitos reservados. É proibida a reprodução total ou parcial, de qualquer forma ou por qualquer meio eletrônico ou mecânico, inclusive através de processos xerográficos, de fotocópias ou de gravação, sem permissão por escrito do possuidor dos direitos de cópias (Lei nº 9.610, de 19.02.1998).

\section{Editora Fórum Ltda}

Av. Afonso Pena, 2770 - 15\%16ªndar - Funcionários

CEP 30130-007 - Belo Horizonte/MG - Brasil

Tel.: 08007043737

Internet: www.editoraforum.com.br

e-mail: editoraforum@editoraforum.com.br
Editor responsável: Luís Cláudio Rodrigues Ferreira Projeto gráfico e diagramação: Luis Alberto Pimenta Revisora: Olga M. A. Sousa

Pesquisa jurídica: Fátima Ribeiro - OAB/MG 74868

Bibliotecária: Alessandra Rodrigues da Silva CRB 2778/MG 6a Região

Os conceitos e opiniões expressas nos trabalhos assinados são de responsabilidade exclusiva de seus autores.

Impressa no Brasil / Printed in Brazil

Distribuída em todo Território Nacional 


\title{
Dilemas do constitucionalismo contemporâneo: é possível uma Constituição para a União Européia? ${ }^{1}$
}

\author{
Raphael Peixoto de Paula Marques \\ Especialista em Direito Constitucional pela UNIPÊ/PB. Professor de Direito Constitucional do Centro \\ Universitário do Distrito Federal/UniDF. Procurador Federal lotado no FNDE/DF
}

\begin{abstract}
Sumário: 1 Introdução - 2 Fundação e desenvolvimento histórico-institucional da União Européia - 3 Constituição Européia: superação dos velhos dogmas ou inocência teórica? 4 Conclusão - Referências
\end{abstract}

Palavras-chave: União Européia. Unificação política. Constituição Européia. Processo de integração. Teoria da Constituição. Teoria do Estado. Patriotismo constitucional.

\section{Introdução}

Toda a experiência jurídica fundamentada na compreensão contemporânea do Direito arrima-se em três critérios básicos: estatalidade, racionalidade e unicidade. Nesse contexto, o Direito identifica-se como a norma imposta apenas pelo Estado, dotada de validade e eficácia no seu âmbito territorial e concebida segundo postulados de coerência e sistematização. ${ }^{2}$ Dentro desta ordem de idéias, o estudo de categorias como Estado, Constituição, Povo, Soberania, entre outros, são fundamentais para se entender esse modelo de Direito que já vigora desde o início da Idade Moderna. Como se não bastassem tais razões, Estado e Constituição mantêm entre si uma relação de referência/interferência recíproca: "a Constituição pretende dar forma, constituir ou conformar um dado esquema de organização política". ${ }^{3}$

No entanto, tal paradigma jurídico vem se transformando devido aos ventos soprados pela integração regional, globalização e universalidade dos direitos humanos. O Estado nacional passou a ser visto como apenas mais uma ordem, seja jurídica, política ou econômica, diante do surgimento de novos organismos supranacionais. Dentre os modelos de integração

\footnotetext{
O presente artigo foi apresentado na disciplina Jurisdição Constitucional Brasileira, ministrada pelo Professor Doutor Gilmar Ferreira Mendes, com a finalidade de adquirir créditos para o mestrado em Direito, Estado e Constituição da UnB.

2 FRANCA FILHO, 2002, p. 1.

3 CANOTILHO, 2002, p. 87.
}

A \& C R. de Dir. Administrativo e Constitucional, Belo Horizonte, ano 6, n. 24, p. 141-162, abr./jun. 2006 
emergentes, a unificação política da União Européia destaca-se por ser a experiência mais avançada institucionalmente. ${ }^{4}$

Um olhar sobre alguns problemas da integração européia propicia uma reflexão que transcende ao caso europeu e interessa à teoria constitucional, à teoria política e ao debate sobre novas dimensões da teoria democrática contemporânea. Essa novidade política, estruturada por instituições que não se comprometem em realizar interesses intergovernamentais ou internacionais, mas apenas o interesse comunitário, exige esforços teóricos em favor de modos alternativos ao modelo estatal de constituição de legitimidade da ação política, justificação do poder e identidade coletiva. ${ }^{5}$

Com efeito, dentro desse processo de integralização de modelos culturais, políticos, econômicos e jurídicos distintos, surge a possibilidade de promulgação de uma Constituição Européia. Fala-se, portanto, da europeização do Estado Constitucional. ${ }^{6}$ Dentro desse espírito, questionase, comparando com a força do constitucionalismo americano, se a futura Constituição européia, neste início de século XXI, terá a capacidade de iniciar um novo constitucionalismo. Já fazendo apostas nesse jogo político, pode-se encontrar o debate entre o que Jürgen Habermas chama de eurocéticos (Euroskeptiker), o pró-mercado europeu, os eurofederalistas e os partidários de um global governance. ${ }^{7}$

Percebe-se, pois, que a possível instituição de uma Constituição, no sentido moderno da expressão, para a União Européia, influenciará toda a teoria constitucional e política construída até agora. Até o surgimento dessa pretensão européia, os termos Constituição, Estado e Soberania andavam juntos e se auto-relacionavam. Com o surgimento do constitucionalismo europeu, já se pode questionar a necessária relação entre os termos Constituição/Estado, cidadania/nacionalidade, Constituição/povo e tantas outras vinculações teóricas.

Por outro lado, o debate acerca da adoção de um texto constitucional para a União Européia é diretamente relacionado ao problema do seu déficit democrático. Embora os cidadãos dos Estados nacionais tenham seus interesses atingidos pela normatização da União Européia, a influência do Parlamento europeu - que é eleito diretamente pelo povo - na

\footnotetext{
4 A união política, e não somente econômica, tem seu marco inicial com a assinatura do Ato Único Europeu em 1986.

5 TOSTES, 2001, v. 23

HABERLE, 2000, n. 2; HABERLE, 2004, n. 1

HABERMAS, 2001, p. 113.
}

A \& C R. de Dir. Administrativo e Constitucional, Belo Horizonte, ano 6, n. 24, p. 141-162, abr.jun. 2006 
estrutura e organização política da UE é mínima. ${ }^{8}$ Além do mais, esse déficit democrático está relacionado com as dificuldades em se construir uma democracia transnacional ${ }^{9}$ devido à inexistência de uma base social européia comum. Tal fato se alinha à valorização de elementos culturais e a constituição de identidades na arena política, considerando a democracia como um processo duplo, envolvendo tanto Estado como sociedade civil. ${ }^{10}$

O debate constitucional europeu, portanto, caracteriza-se como tema de importância mundial - e não só européia. Além do impacto conceitual e teórico que uma possível Constituição para a Europa acarretará, a discussão mostra-se relevante para o contexto brasileiro, na medida em que revisita conceitos como nação, povo, Estado, além, é claro, de estar afeto à própria construção de uma identidade constitucional. ${ }^{11}$

\section{Fundação e desenvolvimento histórico-institucional da União Européia}

Obviamente, antes de falar sobre uma possível Constituição Européia, ter-se-á que entender o surgimento da própria organização supranacional denominada União Européia (UE), bem como sua evolução históricoinstitucional. A partir dessa compreensão, essencial se faz, também, a demonstração das várias tentativas de instituição de uma Lei Fundamental para a União Européia.

Além da consolidação de uma unidade européia não poder ser considerada um fenômeno linear e progressivo, já que existiram momentos de entusiasmo e isolamento entre as nações, ${ }^{12}$ a intenção por uma integração dos Estados da Europa não é nova. Renato de Medeiros Barbosa ${ }^{13}$ afirma que, já nos anos de 1305 e 1307, o publicista normando Pierre Dubois já defendera a formação de uma confederação dos Estados europeus. Mais de duzentos anos depois, no início do século XVII, o duque francês Maximiliano de Béthune Sully, que era conselheiro e ministro de Henrique IV, delineou a imagem de um equilíbrio europeu entre quinze Estados, sendo fundado na Europa uma federação na forma de uma república cristã liderada pela França. ${ }^{14}$ A partir daí, até o século XX, não faltaram adeptos à causa pró-federação, como o Abade francês Saint-Pierre

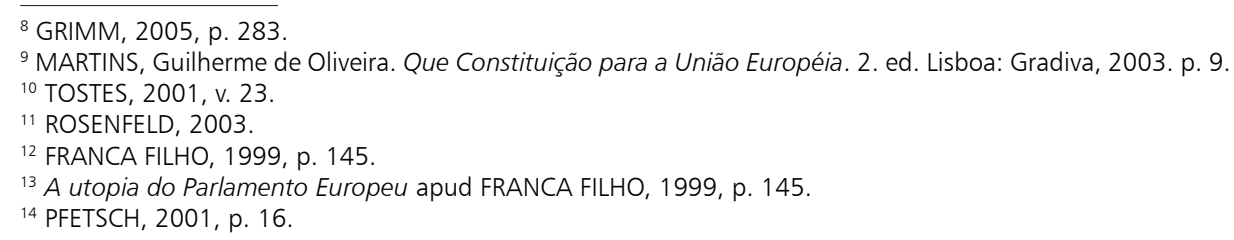

A \& C R. de Dir. Administrativo e Constitucional, Belo Horizonte, ano 6, n. 24, p. 141-162, abr./jun. 2006 
(associação federativa de Estados europeus - 1713), o filósofo Immanuel Kant (organização federal da Europa com Estados republicanos - 1795), o conde de Saint-Simon (comunidade européia com um parlamento universal - 1814) e o escritor Victor Hugo (Estados Unidos da Europa - 1849). ${ }^{15}$

Lançando o olhar sobre o século XX, precisamente em 1924, o Movimento Pan-Europeu, fundado pelo conde austríaco Coudenhove Kalergi, reivindicou a criação dos "Estados Unidos da Europa". Já em 1930, um pouco antes da segunda guerra mundial, o chanceler francês Aristide Briand e o chanceler alemão Gustav Streseman, manifestaram-se, na Sociedade das Nações - posteriormente denominada de Organização das Nações Unidas (ONU) - a favor de uma "União Federal Européia", o que nunca veio a acontecer. ${ }^{16}$

Após o fim da segunda guerra mundial, inicia-se uma nova fase para a Europa. Os projetos europeus de integração, até então reduzidos às relações comerciais bilaterais ou alianças militares, passaram a pugnar, também, por uma maior integração política. Com o fim da guerra e diante de uma Europa massacrada, humilhada e sem recursos para sua reconstrução, os países da Aliança trataram de configurar uma nova Europa no encontro de Ialta. ${ }^{17}$ Segundo Franca Filho, dois fatores conferiram um impulso renovado à aproximação dos Estados Europeus: "a debilidade do continente, que, após duas guerras, havia perdido o posto de principal cenário político e econômico mundial para os Estados Unidos e a União Soviética" e "a imperativa necessidade de se evitarem novos conflitos, mantendo-se a paz a todo custo". ${ }^{18}$ É a partir desse contexto histórico que se inicia o desenvolvimento da atual estrutura da União Européia. Acerca desse início, ilustrativo é o discurso do Primeiro-Ministro Inglês, Winston Churchill, proferido na Universidade de Zurique, no dia 19 de setembro de 1946:

(...) Em que consiste este remédio soberano? Consiste em recriar a família européia, na medida do possível, e oferecer-lhe uma estrutura que lhe permita desenvolver-se em paz, segurança e liberdade. Temos que construir uma espécie de Estados Unidos da Europa. Só assim é que centenas de milhões de seres hu-

\footnotetext{
${ }^{15}$ PFETSCH, 2001, p. 16-18

${ }^{16}$ FRANCA FILHO, 1999, p. 146.

17 "O objetivo expressado pelos mais entusiastas do momento, os franceses Jean Monnet e Robert Schuman, o italiano Alcide de Gaspari e o alemão Konrad Adenauer, era incrementar o grau de supranacionalidade até alcançar um nível de integração que impediria a reedição das tensões históricas entre as potências européias. A internacionalização da economia e as comunicações, ademais, fazia inevitável o rápido avanço no caminho de uma Europa de estrutura confederada, que pudesse competir com o novo líder da economia mundial, os Estados Unidos" (VIERA, 2004, p. 88).

${ }^{18}$ FRANCA FILHO, 1999, p. 146.
}

A \& C R. de Dir. Administrativo e Constitucional, Belo Horizonte, ano 6, n. 24, p. 141-162, abr.jun. 2006 
manos terão a possibilidade de recuperar as pequenas alegrias e esperanças que tornam a vida digna de ser vivida. Podemos chegar lá da maneira mais simples. Só precisamos da determinação de centenas de milhões de homens e mulheres em fazer o bem em vez do mal, para receber bênçãos em vez de maldições.

(...) E porque é que não pode haver um agrupamento europeu que ofereça a povos deste poderoso continente distanciados entre si um sentimento de patriotismo mais vasto e de uma espécie de cidadania comum? E porque é que um agrupamento europeu não haveria de ocupar o seu justo lugar no seio dos outros grandes agrupamentos e contribuir para dirigir a barca da humanidade?

(...) Para levar a bom termo a construção dos Estados Unidos da Europa, a sua estrutura deverá ser concebida de forma que o poder material de cada Estado desempenhe apenas um papel secundário. Os Estados pequenos contarão tanto como os grandes e granjearão respeito pelo seu contributo para a causa comum. É possível que os antigos estados e principados da Alemanha, reunidos num sistema federativo por mútuo acordo e conveniência, venham a assumir o seu lugar nas fileiras dos Estados Unidos da Europa.

(...) Mas gostaria de lançar um aviso. Não dispomos de muito tempo. De momento vivemos uma pausa de recuperação. Os canhões calaram-se, os combates terminaram, mas os perigos ainda espreitam. Se quisermos criar os Estados Unidos da Europa - ou seja qual for o nome que se lhes atribua - devemos começar agora. ${ }^{19}$

Posteriormente a essa fase de ideais, inicia-se uma fase de incubação (1945-1950 $)^{20}$ de uma unidade européia, contida entre o fim da guerra e os primeiros passos rumo a uma efetiva integração supranacional. A idéia de uma integração econômica européia começa a ser desenvolvida com a fundação do Conselho da Europa. Os debates sobre a forma que esse organismo deveria ter são relevantes para o debate atual sobre uma Constituição Européia. Carlo Schmid, membro do Conselho da Europa, afirma que esses debates dividiam-se por três grupos: os universalistas, que englobavam na noção de Europa os países do Leste e do Oeste europeus; os constitucionalistas, que exigiam uma Constituição para os Estados Unidos da Europa; e os funcionalistas, que somente uma Europa economicamente integrada é que estabeleceria as bases para um Estado constitucional europeu. ${ }^{21}$

Como lembra Frank Pfetsch ${ }^{22}$ e a própria história, o entendimento que predominou foi o funcionalista, tendo assumido caráter oficial com a fundação, em 1961, da Organização para a Cooperação e Desenvolvimento Econômico (OCDE), que sucedeu a Organização para a Cooperação

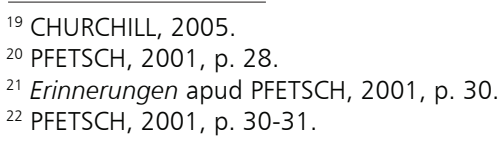

A \& C R. de Dir. Administrativo e Constitucional, Belo Horizonte, ano 6, n. 24, p. 141-162, abr./jun. 2006 
Econômica Européia (OCEE), fundada em 16 de junho de 1948. Nesse momento, é fundamental registrar que esse início de integração econômica européia é, acima de tudo, conseqüência de políticas norte-americanas para a reconstrução da Europa pós-guerra:

Durante a fase de incubação, pois, os planos especificamente europeus não foram itens prioritários da agenda. A integração econômica da Europa começou a tomar forma por causa de considerações de natureza política, em especial da parte dos Estados Unidos. Do lado francês havia em primeira linha o objetivo de vincular a Alemanha a um sistema europeu. Esse motivo levou à constituição da Comunidade Européia do Carvão e do Aço, por iniciativa de Robert Schuman, cujo anúncio marca a transição da fase de incubação para a fase de fundação. Enquanto os interesses norte-americanos na reconstrução da Europa tinham a ver com um contrapeso à formação do bloco soviético, a integração européia servia à política francesa como garantia contra uma possível agressão alemã. A política alemã de Konrad Adenauer, por sua vez, via na integração da Europa ocidental a possibilidade de recuperar a soberania e de viabilizar, com o apoio de um Ocidente forte, no longo prazo, a reunificação. ${ }^{23}$

Com todos esses interesses políticos frutos do massacre da segunda guerra mundial subjacentes a esse impulso integrativo, "o próprio esforço para criar uma Comunidade Européia supranacional única e inventar um senso de identidade européia a ela correspondente, substituindo as velhas lealdades a países históricos", ${ }^{24}$ revelava o declínio do mundo eurocêntrico, impondo, por isso, uma urgente integração dos países afetados profundamente pela guerra.

O processo de integração européia ${ }^{25}$ teve seu início com a declaração de Robert Schuman, ministro francês das Relações Exteriores, em 09 maio de 1950, ${ }^{26}$ com a anunciação da futura criação da Comunidade Européia do Carvão e do Aço (CECA). ${ }^{27}$ A CECA, que teve seu tratado constitutivo subscrito em Paris no dia 18 de abril de 1951, tinha como membros a França, a República Federal da Alemanha, a Itália e o Benelux (Bélgica, Holanda e Luxemburgo). Em sua declaração, Robert Schuman deixava claro as suas intenções e as de Jean Monnet para o futuro da Europa:

\footnotetext{
${ }^{23}$ PFETSCH, 2001, p. 31.

${ }^{24}$ HOBSBAWM, 2002, p. 23.

${ }^{25} \mathrm{~A}$ inovação desse processo de integração é a característica da mediação do Direito. Essa observação já foi feita por Franca Filho: "A principal característica que distancia a União Européia de tentativas anteriores de unificação do Velho Continente (César, Carlos Magno, Napoleão ou Hitler) é justamente a permuta da força física pela força do Direito para a sua instituição e manutenção". Cf. FRANCA FILHO, 2002, p. 65.

${ }^{26}$ Essa data é oficialmente o "Dia da Europa".

27 Pode-se incluir, nessa fase de fundação, a tentativa de elaboração da Comunidade Européia de Defesa (CED) e a Comunidade Política Européia (CPE). Entretanto, em decorrência da oposição francesa, os tratados da CED e da CPE nunca chegaram a ser ratificados.
} 
A Europa não se fará de um golpe, nem numa construção de conjunto: far-se-á por meio de realizações concretas que criem em primeiro lugar uma solidariedade de facto. A união das nações européias exige que seja eliminada a secular oposição entre a França e a Alemanha. Com esse objectivo, o Governo francês propõe actuar imediatamente num plano limitado mas decisivo.

O Governo francês propõe subordinar o conjunto da produção franco-alemã de carvão e de aço a uma Alta Autoridade, numa organização aberta à participação dos outros paises da Europa. A comunitarização das produções de carvão e de aço assegura imediatamente o estabelecimento de bases comuns de desenvolvimento económico, primeira etapa da federação européia, e mudará o destino das regiões durante muito tempo condenadas ao fabrico de armas de guerra, das quais constituiram as mais constantes vítimas. ${ }^{28}$

A Comunidade Européia do Carvão e do Aço, inaugurando formalmente a supranacionalidade ${ }^{29}$ no âmbito das relações interestatais, caracterizou-se como um projeto de grande êxito. Os mesmos seis países, alguns anos mais tarde, em 1957, assinaram o Tratado de Roma, que criou a Comunidade Européia da Energia Atômica (EURATOM) e a Comunidade Econômica Européia (CEE). Essas duas comunidades fundamentaram-se no "Informe Spaak", que foi o produto de uma análise da viabilidade de uma progressiva integração econômica européia realizada por uma comissão intergovernamental de Ministros das Relações Exteriores. $^{30}$

A partir da década de 70, então, começam a surgir as primeiras ampliações às comunidades. Em 22 de janeiro de 1972 surge a Europa dos nove, com a adesão da Dinamarca, Irlanda e Reino Unido. Passando-se pela adesão da Grécia, em 1979, surge, entre 1985 e 1986, a Europa dos doze, com a entrada de Portugal e Espanha. É justamente nessa Europa dos doze, que se realiza a assinatura do Ato Único Europeu em 1986. O Ato Único põe fim a uma fase de imunidade política comunitária contra tentativas de aprofundamentos, que vai de meados dos anos 70 até

\footnotetext{
${ }^{28}$ Declaração Schuman de 09 de maio de 1950. Disponível em: <http://europa.eu.int/abc/symbols/9-may/ decl pt.htm>. Acesso em: 21 jun. 2005.

${ }^{29}$ Sobre a diferença entre supranacionalidade e integração, ilustrativa é a lição de Francisco Javier Donaire Villa, professor de Direito Constitucional da Universidade de Estremadura: "a integração seria uma técnica de relação ou vinculação entre Estado que consiste na cessão de competências a favor da entidade comum criada por eles mesmos, enquanto que a supranacionalidade seria seu resultado, e se identificaria com o exercício dessas competências cedidas por parte das instituições da entidade receptora, qualificada então como supranacional ou comunitária, como na Europa". Cf. VILLA, Francisco Javier Donaire. Constituições nacionais e integração européia. In: HOFMEISTER, 2004, p. 49-70.

${ }^{30}$ Conforme nos relata Franca Filho, juntamente com a assinatura dos Tratados constitutivos da CEE e da CEEA foi subscrito o Convênio sobre Determinações Instituições Comuns às Comunidades Européias, "que representou o primeiro passo para a convergência política entre as três comunidades", ao criar alguns órgãos conjuntos como o Comitê Econômico e Social, o Parlamento e o Tribunal de Justiça. Cf. FRANCA FILHO, 1999, p. 149.
} 
o início dos anos 80, e que ficou conhecida como "euroesclerose". ${ }^{31}$ Esse tratado pode ser considerado a base do Tratado de Maastricht (1992) e do terceiro processo de adesão (1995), com o ingresso da Suécia, da Áustria e da Finlândia. A doutrina ${ }^{32}$ dá grande importância ao Ato Único Europeu, mais especificamente em três aspectos: novo impulso à política econômica da Comunidade, maior eficiência institucional dos organismos comunitários e realização de progressos no campo da política externa.

Já na década de 90, depois da queda do muro de Berlim e diante do surgimento de uma nova ordem mundial e da influência do fenômeno globalização, a Europa se fortalece com a assinatura do Tratado de Maastricht no dia 07 de fevereiro de 1992. O Tratado de Maastricht alterou a designação da Comunidade Econômica Européia para simplesmente Comunidade Européia. Introduziu, igualmente, novas formas de cooperação entre os governos dos Estados. Ao acrescentar esta cooperação intergovernamental ao sistema comunitário existente, o Tratado de Maastricht criou uma nova estrutura com três pilares ${ }^{33}$ de natureza tanto política como econômica. Tratava-se da União Européia (UE).

Embora assinado em 1992, o Tratado de Maastricht não entrou imediatamente em vigor, devido a inúmeras dificuldades encontradas na Dinamarca, França, no Reino Unido e na Alemanha. ${ }^{34}$ Nesse último país especificamente, a demora na ratificação do tratado deu-se em virtude da famosa decisão Maastricht ${ }^{35}$ do Tribunal Constitucional Federal alemão, de 12 de outubro de 1993. Embora o BVerfGE - assim como a Suprema Corte da Dinamarca em processo semelhante — não tivesse declarado a inconstitucionalidade ${ }^{36}$ do tratado, fixou alguns limites constitucionais para a ratificação das posteriores alterações de tratados:

\footnotetext{
31 PFETSCH, 2001, p. 52

32 PFETSCH, 2001, p. 55-56. Vide, também, FRANCA FILHO, 1999, p. 149; VIERA, 2004, p. 100-101; WEILER, 1995.

${ }^{33}$ Nas fases preparatórias do Tratado de Maastricht esboçavam-se duas fases distintas de integração: o esquema do "templo" (inclusão de novos campos da política segundo o modelo das colunas de um templo), defendido pela França, Inglaterra, Dinamarca, Grécia, Espanha e Portugal, e o esquema da "árvore" (ampliação das competências dos organismos comunitários com diferentes modalidades de decisão e execução) defendido pela Bélgica, Holanda, Alemanha e Itália. Ao final, a tendência vencedora foi a dos templários, em detrimento dos botânicos. A União Européia passou a se assentar em três pilares: as Comunidades Européias (supranacionalidade), a política externa e de segurança comum e a cooperação em matéria de política interna e justiça (intergovernabilidade). Cf. PFETSCH, 2001, p. 58-59.

${ }^{34}$ Conforme registra Franca Filho, "na verdade, o grande empecilho para a aprovação de Maastricht nos países membros da recém-criada União Européia residiu no fato de que as transformações estruturais intentadas por aquele Tratado atingiam a própria essência do que se concebe como Estado (a Staatlichkeit da doutrina alemã): cidadania, política econômica, moeda, política externa, entre outros. Apenas se modificadas as ordens jurídicas nacionais poder-se-ia legitimar a instituição da União Européia" (FRANCA FILHO, 1999, p. 150).

35 Sentença 20 EuGRZ 429 (1993), 12 de outubro de 1993.
}

A \& C R. de Dir. Administrativo e Constitucional, Belo Horizonte, ano 6, n. 24, p. 141-162, abr.jun. 2006 
1) O direito alemão proíbe a diminuição do poder do Estado através da transferência de deveres e responsabilidades do Parlamento Federal, na extensão em que isso importar em violação do princípio democrático.

2) O princípio democrático não impede que a República Federal da Alemanha se torne membro de uma comunidade intergovernamental organizada em base supranacional.

3) Se uma comunidade de Estados assume poderes e responsabilidades de soberania, os povos dos Estados-membros precisam legitimar esse processo através dos seus parlamentos nacionais.

4) O princípio democrático impõe limites à extensão de funções e poderes a serem transferidos para a comunidade européia. O Parlamento Federal deverá reter funções e poderes de importância substancial.

5) O programa de integração e os direitos transferidos à comunidade européia supranacional devem ser especificados com precisão. Cabe ao Tribunal Constitucional Federal determinar se os direitos de soberania exercidos pelas instituições e entidades dirigentes européias estão dentro dos limites ou se extrapolam os que lhes foram conferidos.

6) A interpretação das regras de competência do Tratado de Maastricht não deverá importar em extensão do Tratado. Se tal ocorrer, a Alemanha ficará vinculada.

7) O Tribunal Constitucional Federal e a Corte Européia de Justiça exercem jurisdição em uma "relação cooperativa".

8) O Tratado de Maastricht estabelece uma comunidade intergovernamental para criação de uma unidade mais estreita entre os povos da Europa. Cada um desses povos é organizado em um Estado próprio, inexistindo, pois, um Estado da Europa, com seu próprio povo.

9) a) O Tratado de Maastricht não confere à União Européia autodeterminação na obtenção de recursos, financeiros ou de qualquer outra natureza, destinados a atender seus objetivos. É necessário o consentimento dos Estados.

b) A ratificação do Tratado não sujeita a República Federativa da Alemanha a um processo incontrolável e imprevisível que conduza inexoravelmente à unificação monetária. O Tratado de Maastricht simplesmente prepara o caminho para a integração gradual da Comunidade Européia em uma comunidade de leis. Qualquer passo adiante depende do consentimento do Governo Federal, sujeito à deliberação do Parlamento. ${ }^{37}$

\section{Dando continuidade ao processo de integração, e conforme}

\footnotetext{
${ }^{36}$ Acerca da declaração de inconstitucionalidade de tratados, ao contrário do que possa parecer de início, o tema não é incomum. Declarações de inconstitucionalidade foram realizadas sobre o Ato Único Europeu (Irlanda), sobre o Tratado de Maastricht (França e Espanha) e sobre o Tratado de Amsterdam (França). Cf. WITTE, 2004. Sobre a relação entre o direito comunitário e o direito nacional, no âmbito da atuação dos Tribunais Constitucionais, vide as decisões Apesco na Espanha; Frontini v. Ministero delle Finanze, Acciaierie S. Michele v. Ceca, Granital, SpA Fragd v. Ministero delle Finanze, na Itália e MaCarthys Ltd v. Smith, na Inglaterra. Na doutrina, cf. CRAIG, n. 95/29; GARCíA, 2002, n. 104.
} 
previsto no art. n.2 do Tratado de Maastricht, foi realizada, entre 1996 e 1997, a Conferência Intergovernamental (CIG) que resultou na assinatura do Tratado de Amsterdam (02.10.1997), que reformou grande parte do Tratado da União Européia e do Tratado da Comunidade Européia. É justamente por meio do Tratado de Amsterdam ${ }^{38}$ que se procurou solucionar dois dos maiores problemas da União Européia: déficit democrático ${ }^{39} \mathrm{e}$ falta de sistematização e clareza dos tratados. ${ }^{40}$ No entanto, o problema parece continuar, sobretudo tendo em vista a quantidade de artigos que possui o Tratado que estabelece uma Constituição Européia.

Em 26 de fevereiro de 2001, foi assinado o Tratado de Nice, que introduziu novas alterações nos Tratados da UE e CE, modificando o modo de funcionamento das instituições e tornando a votação por maioria qualificada a regra (em vez da unanimidade) em muitas áreas de decisão da UE. ${ }^{41} \mathrm{O}$ mandato da CIG que culminou no Tratado de Nice era preparar a União Européia para o alargamento, o que necessitava a revisão dos Tratados em quatro domínios fundamentais: dimensão e composição da Comissão Européia; ponderação dos votos no Conselho; alargamento das votações por maioria qualificada; cooperações reforçadas. Para o debate constitucional europeu o importante não era o Tratado de Nice em si, mas as declarações e protocolos em anexo. Os protocolos possuem o mesmo valor jurídico que o tratado, enquanto que as declarações são meros ideais políticos.

Os protocolos são quatro: Protocolo relativo ao alargamento da União Européia (UE), Protocolo relativo ao Estatuto do Tribunal de Justiça e do Tribunal de Primeira Instância, Protocolo relativo às conseqüências financeiras do termo de vigência do Tratado que institui a Comunidade

\footnotetext{
37 BARROSO, 2002, p. 26-27.

${ }^{38}$ Os quatro grandes objetivos do Tratado de Amsterdam, segundo Franca Filho, eram: colocar o emprego e os direitos dos cidadãos no centro das atenções da União Européia; suprimir os últimos entraves à livre circulação de pessoas e reforçar a segurança no espaço comunitário; conceder à União a possibilidade de ter voz própria nas questões internacionais; e tornar mais eficiente a arquitetura institucional da União. Cf. FRANCA FILHO, 1999, p. 153-154.

${ }^{39}$ Sobre o déficit democrático da União Européia e a impossibilidade de uma Constituição Européia, cf. GRIMM, 2005, p. 282-302.

${ }^{40}$ Acerca da falta de sistematização e da quantidade de tratados, bem como do tamanho do Tratado que estabelece uma Constituição Européia, vide KLABBERS, 2003, n. 12.

${ }^{41}$ Novas alterações serão provavelmente introduzidas nos Tratados posteriormente à Convenção sobre o Futuro da Europa e ao Tratado de Adesão dos dez novos Estados-Membros, cuja assinatura foi efetuada em 16 de Abril de 2003, com entrou em vigor em 1 de Maio de 2004. Esse novo processo de alargamento, um dos mais importantes, levando em conta a adesão de países do leste europeu, proporcionou o ingresso de Chipre, Eslováquia, Eslovênia, Estônia, Hungria, Letônia, Lituânia, Malta, Polônia e República Checa. A Europa passa a ser "Europa dos vinte e cinco". Sobre esse alargamento e a possibilidade de uma conseqüente relação da identidade européia com laços culturais ou até mesmo limites geográficos, vide LUCAS, 07/2004.
} 
Européia do Carvão e do Aço (Tratado CECA) e Protocolo relativo ao artigo 67 do Tratado que institui a Comunidade Européia. As declarações são vinte e quatro, mas o que nos interessa mais de perto é a declaração que centra a atenção no futuro da Europa. A Declaração no 23 de Laeken possuía como temas de reflexão a delimitação das competências, o estatuto da carta dos direitos fundamentais, a simplificação dos tratados e o papel dos parlamentos nacionais. Essa declaração teve o mérito, no processo pós-Nice, de convocar uma convenção para estabelecer uma CIG (conferência intergovernamental) para debater os problemas essenciais colocados pelo futuro desenvolvimento da União e analisar as diferentes soluções possíveis. ${ }^{42}$ Abria-se, dessa maneira, o debate sobre a elaboração de uma Constituição — com todas as implicações que esse termo carrega ${ }^{43}$ - para a Europa.

A sessão inaugural da Convenção teve lugar em 28 de fevereiro de 2002 e os seus trabalhos foram concluídos em 18 de Julho de 2003, com a apresentação do projeto final de tratado que estabelece uma Constituição para a União, pelo seu Presidente, Valéry Giscard d'Estaing, à Presidência italiana. Concretizava-se, após longo processo de integração comunitária voltado para o cenário econômico, o ansiado projeto políticoconstitucional, que passou a ocupar o centro dos debates europeus. Podese concluir, portanto, que o processo de integração ocupou-se, durante várias décadas, do âmbito econômico, sobretudo pelo receio em avançar o debate sobre dogmas como soberania, povo, nação, Estado, Constituição etc. O debate constitucional europeu parece ganhar fôlego a partir de 2000, mais precisamente com a elaboração da Carta de Direitos Fundamentais de $\mathrm{Nice}^{44}$ que, embora se caracterize apenas como uma declaração política, rompe com o método intergovernamental iniciado com Robert Schuman e Jean Monnet, para iniciar um novo método, o constitucional. ${ }^{45}$ 3 Constituição Européia: superação dos velhos dogmas ou inocência teórica?

A União Européia necessita de uma Constituição? Essa é a pergunta que tem atraído a atenção dos juristas, políticos, economistas, cidadãos europeus, desde que o projeto Giscard d'Estaing ${ }^{46}$ se converteu no Tratado

\footnotetext{
${ }^{42}$ Para o acesso a todos os documentos que envolvem o debate, vide o site da União Européia. Disponível em: <http://europa.eu.int>.

${ }^{43}$ Para Jürgen Habermas, as palavras possuem um poder simbólico relevante. Desse modo, o termo Constituição poderia exercer uma influência determinante na criação de um espaço público europeu de cidadãos. Sobre o assunto, cf. HABERMAS, 2001; WEINER, 5/04.

${ }^{44}$ Especificamente sobre o tema dos direitos fundamentais na União Européia cf. LUQUE, 2004, p. 11-27; MALLEN, 2004, p. 27-49; SCHUTTER, 7/04.

${ }^{45}$ DUARTE; VIEIRA, 2005, p. 300-301; PAGLIARINI, 2005, p. 16-17.
}

A \& C R. de Dir. Administrativo e Constitucional, Belo Horizonte, ano 6, n. 24, p. 141-162, abr.jun. 2006 
que estabelece uma Constituição Européia. O presente estudo não pretende realizar um exame detido sobre o tratado em si, mas sobre algumas questões afetas à Teoria da Constituição e do Estado: (i) se pode haver Constituição sem povo e Estado; (ii) se existe um poder constituinte supranacional; (iii) se este poder poderia manifestar-se através de uma convenção e (iv) como dar-se-á a relação entre Constituição Européia e Constituição nacional. Deste modo, analisar-se-ão alguns obstáculos que são levantados contra a possibilidade da União Européia ter uma Constituição, no sentido atribuído ao termo pelo constitucionalismo iniciado há duzentos anos com as revoluções liberais, mais notadamente a Revolução Francesa e Americana.

Mas, como e quando começou esse debate? Embora o Tratado que estabelece uma Constituição Européia tenha sido assinado em 2004, o debate constitucional não é recente, nem possui um consenso. Mais especificamente centrado numa Constituição formal, as discussões sobre um espaço constitucional europe $u^{47}$ situam-se nos primeiros anos da década de 90 com os diversos informes elaborados no Parlamento Europeu que culminaram na apresentação de um texto constitucional em fevereiro de 1994. ${ }^{48}$ A partir daí, durante esses onze anos, a questão constitucional européia já envolveu juristas do porte de Dieter Grimm, Ingolf Pernice, Peter Häberle, A. Bogdandy, Michel Rosenfeld, Mark Tushnet, Joseph Weiler, Pedro Villalón, Rodriguez Iglesias, Diez-Picaso, Gustavo Zagrebelsky, Maurizio Fioravanti, Gomes Canotilho, Poiares Maduro, Jaqueline Dutheil de La Rochère, filósofos como Jürgen Habermas, Alain Touraine, e juristas brasileiros como Menelick de Carvalho Neto e José Ribas Vieira. ${ }^{49} \mathrm{O}$ debate se arrefece a partir de 2000 com a proclamação da Carta de Direitos Fundamentais de Nice, bem como com uma conferência de Joschka Fischer na Universidade de Humboldt em maio de 2000, ${ }^{50}$ culminado

\footnotetext{
46 J.J. Gomes Canotilho enumera os projetos de Constituição Européia produzidos a partir de Nice: Projeto de Badinter (setembro de 2002), Projeto D.L. Garrido (setembro/outubro de 2002), Projeto A. Dashwood (outubro de 2002), Projeto E. O. Paseiotti (outubro de 2002), Projeto verde de Von Seifert (setembro de 2002), Projeto F. Dehousse e W. Coussens (setembro de 2002), Projeto Von. J. Leinen (outubro de 2002). Projeto CDU/CSU (novembro de 2001), Projeto de Berlim (novembro de 2002 - Gloser/Roth), Projeto Frascuti (novembro de 2002 - Partido Popular Europeu), Manifesto da Comissão Lambodorf (novembro de 2002), Projeto dos professores R. Scholtz e J.S. Schawarz/J. Flauss, Projeto E. Brok, Projeto Prodi (Projeto Giscard). Cf. CANOTILHO, José Joaquim Gomes. Aproximação às Soberanias: Estado, Povo, Cidadão. In: Tópicos para uma Intervenção no VI Curso de História Contemporânea, Fundação Mário Soares. Disponível em: <http://www.fd.uc.pt/docentes/jjgc/aproximacaoassoberanias.pdf>. Acesso em: 18 maio 2005

${ }^{47}$ VILLALÓN, 2004, p. 13

${ }^{48}$ Cf. PETESMANN, E.U. How can the European Union be Constitutionalized? The European Parliament's 1994 Proposal for a Constitution the European Union. Apud VILLALÓN, 2004, p. 18.
} 
na convenção que elaborou um projeto de tratado constitucional. Vê-se, assim, que o debate está longe de chegar a um ponto arquimediano. As questões divergentes são inúmeras.

A primeira crítica feita é a de que a Europa não possui um povo europeu e não se caracteriza como um Estado e, por isso, não poderia ter uma Constituição. Esse tema tem desenvolvimento em um interessante debate entre Dieter Grimm ${ }^{51}$ e Jürgen Habermas. ${ }^{52}$ Dieter Grimm começa seu raciocínio afirmando que as Constituições formam a base jurídica dos Estados e que as instituições supranacionais, ao contrário, têm sua base jurídica em tratados internacionais. ${ }^{53}$ Afirma o jurista alemão que essa distinção apenas se torna equivocada se se considerar os tratados constitutivos da UE como sendo a sua "Constituição", como já vem fazendo a jurisprudência do Tribunal de Justiça Européia. Essa afirmação traduz a idéia de que a União Européia já possui uma Constituição no sentido material, ${ }^{54}$ isto é, uma living Constitution..$^{55}$

Nesse contexto, afirma Grimm que a única semelhança entre a Constituição Européia e as Constituições nacionais é apenas formal, ou seja, o uso do mesmo termo. Para Grimm, o objetivo da Constituição da Europa é diverso daquelas que foram forjadas a partir das revoluções liberais francesa e americana. A noção de Constituição seria, assim, indissociável da noção de Estado. Embora a União Européia exerça parcela da soberania dos Estados, não se caracteriza, de forma alguma, como um deles.

Por fim, e como argumento principal, Grimm expõe que não pode haver Constituição Européia pelo simples fato de que haveria a ausência de um espaço público europeu, ${ }^{56}$ bem como a inexistência de um povo europeu (no-demos-thesis). ${ }^{57}$ Ambos estão inter-relacionados, já que na medida em que na Europa não se encontra, ainda, um debate público consolidado acerca do europeu como uma cidadania cumulativa, dos direitos comuns albergados no âmbito supranacional, não se pode falar, também, da existência de um povo europeu. Embora não vinculado a um conceito de povo schmittiano, ${ }^{58}$ Grimm afirma que na Europa ainda

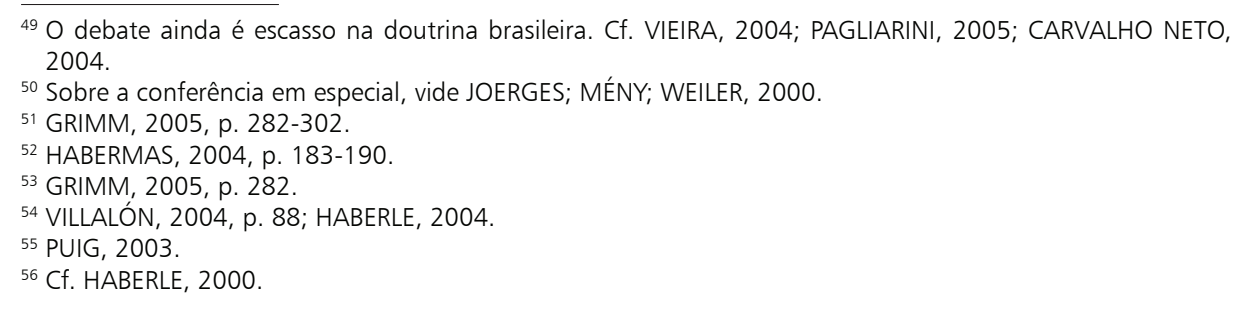

A \& C R. de Dir. Administrativo e Constitucional, Belo Horizonte, ano 6, n. 24, p. 141-162, abr.jun. 2006 
não haveria uma esfera pública capaz de conferir legitimidade a uma Constituição. Essa inexistência de uma identidade comum européia traz inconvenientes como a reativação de velhas imagens fronteiriças, como xenofobias e localismos, ${ }^{59}$ além de uma automização de órgãos supranacionais. ${ }^{60}$ Para isso, argumenta que o Parlamento Europeu não exerce as mesmas funções básicas dos Parlamentos Nacionais. Para ele, a UE teria um esquema político-institucional desigual, com maior concentração de competências nas mãos do executivo, isto é, do Conselho Europeu.

Por outro lado, Dieter Grimm expõe outro obstáculo à formação de uma democracia de âmbito supranacional: a questão da língua. Ora, em um ambiente onde os indivíduos não podem se comunicar, não pode haver construção social. ${ }^{61}$

Por sua vez, Habermas, ${ }^{62}$ em reposta a Dieter Grimm, parte do mesmo prognóstico, porém chegando a outras alternativas possíveis. O filósofo alemão concorda com a análise da situação feita por Grimm, ou seja, falta ao Parlamento Europeu maior influência na tomada de decisão européia, bem como que ainda não há uma esfera pública européia adequada. No entanto, Habermas afirma que,

A opção de Grimm parece sugerir que o status quo do direito público pode ao menos congelar o déficit democrático hoje existente. Com total independência em relação a inovações do direito constitucional, porém, esse déficit continua aumentando dia após dia, e isso porque a dinâmica econômica e social, no âmbito institucional ora dado, continua impulsionando o desgaste das competências dos Estados nacionais por parte do direito europeu. (...) Mas se de qualquer maneira continua aumentando a disparidade entre os crescentes poderes decisórios das autoridades européias e a legitimação precária das regulamentações européias, que continuam a adensar-se, a decisão inflexível pelo modo de legitimação exclusivamente ligado aos Estados nacionais não significa simplesmente a escolha de um mal menor. Os federalistas assumem como um desafio o risco (previsto, e muitas vezes evitável) de uma autonomização de organizações supranacioanais. ${ }^{63}$

Por outro lado, rebatendo o argumento de que não existe um povo europeu, expõe Habermas que

O argumento que afirma a inexistência de um "povo" europeu e que, portanto,

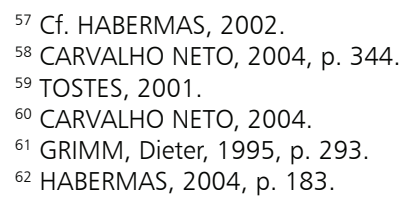

A \& C R. de Dir. Administrativo e Constitucional, Belo Horizonte, ano 6, n. 24, p. 141-162, abr.jun. 2006 
não existe um poder legislador ganha o caráter de uma objeção fundamental apenas a partir de um determinado uso do conceito de "povo". O prognóstico que afirma que não haverá algo como um povo europeu seria plausível se a forca criadora de solidariedade do "povo" de fato dependesse da base de confiança pré-política de uma comunidade "amadurecida" que os compatriotas como que herdariam com o seu "destino de socialização". ${ }^{64}$

Dessa forma, o que estaria faltando seria uma esfera pública, uma cidadania européia, para legitimar uma base política supranacional. $\mathrm{O}$ problema não seria a inexistência de povo, já que se trata de noção que deve ser entendida exclusivamente no sentido político-jurídico - desvinculada de laços de natureza étnico-cultural ${ }^{65}$ - e não no sentido de povo-ícone. ${ }^{66}$ Assim,

(...) o próximo impulso no sentido da integração numa sociabilização pós-nacional não depende do substrato de algum povo europeu, mas das redes de comunicação de uma opinião pública política de alcance europeu, enfronhada numa cultura política comum, sustentada por uma sociedade civil com associações de interesses, organizações não governamentais, iniciativas e movimentos cívicos, e que seja assumida pelas arenas nas quais os partidos políticos possam se referir imediatamente às decisões das instituições européias, para além das alianças de bancadas, até chegarem a ser um sistema partidário europeu. ${ }^{67}$

Nesse sentido, Habermas propõe um patriotismo constitucional, onde a Constituição seria o centro de mobilização ou integração política da sociedade. Pareceria faltar apenas uma Constituição Européia para desencadear um contexto comunicacional formador de uma autocompreensão ético-político dos cidadãos:

A cultura política de um país cristaliza-se em torno da constituição em vigor. Toda ${ }_{63}$ HABERMAS, 2004, p. 185 . 64 HABERMAS, 2001.

65 Para Habermas, "a nação tem duas faces. Ao passo que a nação dos cidadãos ligados ao Estado, fruto da vontade, é fonte de legitimação democrática, a nação de compatriotas, gerada de maneira espontânea, prove a integração social. Os cidadãos, por forca própria, constituem a associação política entre os livres e iguais; os compatriotas encontram-se em uma comunidade cunhada por uma língua e historia em comum. Permitiu-se que a tensão entre o universalismo de uma comunidade jurídica igualitária e o particularismo de uma comunidade histórica que partilha um mesmo destino ingressasse na conceitualidade do Estado nacional. Essa ambivalência só não oferece perigo, enquanto um entendimento cosmopolita de nação de cidadãos vinculados ao Estado puder prevalecer sobre a interpretação etnocêntrica de uma nação que se encontra em um estado de guerra latente e duradouro. Apenas um conceito nãonaturalista de nação amolda-se sem dificuldades a uma autocompreensão universalista do Estado de direito democrático". Cf. HABERMAS, 2004, p. 138.

66 "O povo como ícone, erigido em sistema, induz a práticas extremadas. A iconização consiste em abandonar o povo a si mesmo; em desrealizar [entrealisieren] a população, em mitificá-la (naturalmente já não se trata já muito tempo dessa população), em hipostasiá-la de forma pseudo-sacral e em instituí-la assim como padroeira tutelar abstrata, tornada inofensiva para o poder-violência - notre bom peuple". Cf. MÜLLER, Friedrich. Quem é o Povo: a Questão Fundamental da Democracia. 2. ed. Tradução de Peter Naumann. São Paulo: Max Limonad, 2000. p. 67.

${ }^{67}$ HABERMAS, 2004, p. 182.

A \& C R. de Dir. Administrativo e Constitucional, Belo Horizonte, ano 6, n. 24, p. 141-162, abr.jun. 2006 
leitura diferente para os mesmos princípios - tais como soberania do povo e direitos humanos - , os quais também se corporificam em outras constituições republicanas. Sobre a base dessa interpretação, um "patriotismo constitucional" pode ocupar o lugar do nacionalismo original. ${ }^{68}$

Com relação ao entendimento de Dieter Grimm sobre a inexistência de uma língua comum, Habermas argumenta que a exigência de uma língua comum não seria um obstáculo, tendo em vista a situação atual da educação escolar formal nos países europeus, podendo, sem problema algum, adotar o inglês como second first language ${ }^{69}$

Levando em conta todas essas considerações habermasianas, podese afirmar que os obstáculos levantados contra um possível poder constituinte supraconstitucional, bem como à impossibilidade de equiparação de uma convenção com uma assembléia constituinte, caem por terra. Isso porque o próprio sentido francês de poder constituinte criado por Sieyés, até hoje bastante influente entre nós, tem que ser devidamente contextualizado na pós-modernidade. Primeiro, esse modelo francês não pode ser entendido como o único adequado, tendo em vista justamente à diversidade de tradições constitucionais, principalmente na Europa. ${ }^{70}$ Segundo, a legitimidade de uma Constituição não pode mais ser aferida diante do momento constitucional, já que a própria noção de legitimidade e identidade constitucional revelam-se como um constructo, uma noção aberta para o futuro, sendo permanentemente posto ao teste da legitimação democrática. ${ }^{71}$ Sobre o assunto, instigante é a indagação que nos faz Marcelo Cattoni:

Afinal, qual é o fundamento de legitimidade do projeto constituinte de um Estado Democrático de Direito, senão a própria construção, e projeção a um futuro aberto, dessa legitimidade? E de uma legitimidade através da legalidade, do reconhecimento segundo o qual se deve, inclusive, rever a concepção francesa e tradicional de poder constituinte como ato de força e compreender que, hoje, após mais de dois séculos de Constitucionalismo, o poder constituinte "requer mais do que a simples e bruta tomada do poder ou manipulações palacianas para obter apoio do povo". (...) Enfim, trata-se de um pro-jecto que, por ser moderno, é sempre carente de legitimidade, de uma legitimidade que é sempre vivida como falta, como ausência, na impossibilidade de um fundamento último, absoluto, e que remete a própria questão da legitimidade à idéia de construção da legitimidade, através da realização no tempo da coesão interna entre as noções

\footnotetext{
${ }^{68}$ HABERMAS, 2004, p. 141.

69 HABERMAS, 2004, p. 190.

70 Sobre as diferentes tradições constitucionais do rule of law, Rechstaat, Etat de droit e Estado de Direito, vide ROSENFELD, 2001.

${ }^{71}$ ROSENFELD, 2003
}

A \& C R. de Dir. Administrativo e Constitucional, Belo Horizonte, ano 6, n. 24, p. 141-162, abr.jun. 2006 
de autogoverno e de iguais direitos individuais de liberdade, concretizadores de uma noção complexa de autonomia (....$^{72}$

Com isso, o próprio instrumento formal pela qual se estabelece uma Constituição, seja convenção, ${ }^{73}$ seja assembléia nacional constituinte, perde um pouco de importância diante desse conceito de identidade constitucional aberta, a ser permanentemente legitimada. ${ }^{74}$

Relativamente às objeções relacionadas com a impossibilidade de funcionamento de duas Constituições — Européia e Nacional —, ver-se-á que, embora o próprio termo Constituição tenha surgido para atuar de forma isolada, como protagonista ${ }^{75}$ - já que não se pensava na relação Constituição-Constituição, até pelas próprias características westfalianas dos Estados soberanos —, há, atualmente, formulações teóricas bem avançadas para servir de alternativa à questão. ${ }^{76}$ Antes disso, é preciso deixar registrado duas dificuldades que afloram nesse debate. A primeira é que a relação entre Constituições vai dar-se caso a caso, ao contrário da relação direito comunitário-direito nacional, que se caracteriza pela indiferenciação. Segundo, é o fato de que, justamente no contexto histórico em que a noção constitucional está bem definida (supremacia constitucional), é que surge o desafio de se imaginar a co-existência de duas Constituições. ${ }^{77}$

Procurando afastar essas duas dificuldades é que são propostos alguns modos de compreensão do tema como o constitucionalismo débil de Villalón ${ }^{78}$ e o constitucionalismo de vários níveis de Pernice. ${ }^{79}$

O Constitucionalismo débil de Pedro Cruz Villalón vincula-se, de perto, com o contexto federal e mais especificamente com o contexto espanhol das autonomias regionais. Levando em consideração a pluralidade de ordens constitucionais (européia e nacional), Cruz Vilallón propõe um modelo uma distinção entre constitucionalismo em sentido fraco e constitucionalismo em sentido forte:

El PTCE se apropia prácticamente todas las categorias del constitucionalismo. Al mismo tiempo, el constitucionalismo europeu em sentido estricto, el de la

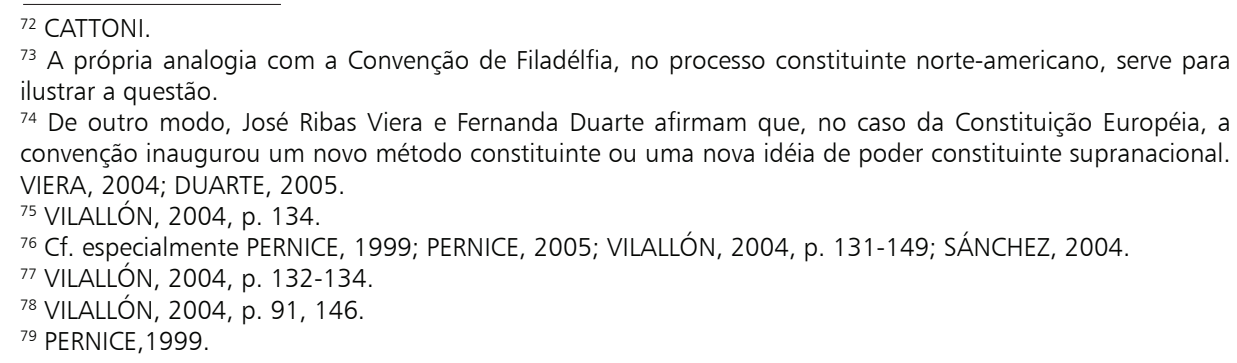

${ }^{73}$ A própria analogia com a Convenção de Filadélfia, no processo constituinte norte-americano, serve para ilustrar a questão.

${ }_{74}$ De outro modo, José Ribas Viera e Fernanda Duarte afirmam que, no caso da Constituição Européia, a convenção inaugurou um novo método constituinte ou uma nova idéia de poder constituinte supranacional. VIERA, 2004; DUARTE, 2005.

${ }^{75}$ VILALLÓN, 2004, p. 134.

${ }^{76}$ Cf. especialmente PERNICE, 1999; PERNICE, 2005; VILALLÓN, 2004, p. 131-149; SÁNCHEZ, 2004.

77 VILALLÓN, 2004, p. 132-134.

${ }^{78}$ VILALLÓN, 2004, p. 91, 146.

79 PERNICE, 1999.

A \& C R. de Dir. Administrativo e Constitucional, Belo Horizonte, ano 6, n. 24, p. 141-162, abr.jun. 2006 
Unión, va a pasar a configurar lo que podríamos llamar um constitucionalismo cualitativamente menor, comparado com el constitucionalismo estatal. Dicho de otro modo, el constitucionalismo de la Unión va a ser por un cierto período de tiempo y hasta cierto punto un constitucionalismo reflejo, dependiente, en el sentido de fuertemente condicionado por una constitucionalidad (...) fuerte, autônoma, representada por los Estados. ${ }^{80}$

Essa distinção entre constitucionalismo forte e fraco seria influenciada pela tradição nacional das autonomias regionais, que oferecem um paradigma de um constitucionalismo comparativamente mais débil.

O constitucionalismo de vários níveis de Pernice (multilevel constitucionalism) assenta-se sobre uma idéia de constitucionalismo complexo ou composto, integrado por uma pluralidade de ordens constitucionais, a ordem constitucional da União e a ordem constitucional dos Estados. Sua proposta plural de ordens constitucionais parte de uma prévia cultura constitucional nacional, onde as Constituições dos estados-membros exercem um certo protagonismo juntamente com a Constituição Federal. Para Pernice, complementar ao seu modelo de constitucionalismo de vários níveis é o que ele chama de União de Constituição, noção que expressa um sentido político (todos os Estados-membros estão submetidos a uma Constituição nacional) e um sentido jurídico (pluralidade de ordens constitucionais européia e nacional). ${ }^{81}$

\section{Conclusão}

Como se deixou registrado no texto, o debate constitucional europeu é inédito. Derrubar todos os dogmas relacionados com a Teoria da Constituição e com a Teoria do Estado, que nos acompanham há duzentos anos, não é fácil. O debate está longe de acabar e de chegar a um consenso.

A noção de patriotismo constitucional formulada por Habermas, que toma a Constituição como um catalisador político com vistas à formação de uma autocompreensão ético-política dos cidadãos europeus, é interessante, na medida em que procura desvincular o conceito de povo de laços étnicos-culturais. Nesse sentido, patriotismo constitucional jamais vai ser configurado com um nacionalismo institucional.

A própria realidade, diante da globalização econômica e de uma exclusão social em massa, mostra que, independentemente de um modelo constitucional específico, sem uma formação de uma esfera pública demo-

80 VILALLÓN, 2004, p. 90, 91.

81 PERNICE, 1999.

A \& C R. de Dir. Administrativo e Constitucional, Belo Horizonte, ano 6, n. 24, p. 141-162, abr.jun. 2006 
cratizada e consciente, a autonomização dos órgãos públicos vai continuar, isso porque o Estado Nacional não consegue mais impor políticas públicas de forma suficiente na pós-modernidade.

Nesse contexto, afigura-se possível o estabelecimento de uma Constituição Européia para servir de impulso a uma rede comunicativa que forme cidadãos europeus. Os argumentos contra um poder constituinte europeu são frágeis diante das noções de identidade constitucional aberta, que requer uma legitimação permanente. Ora, seja num contexto nacional, seja num contexto supranacional, a Constituição revela-se como um projeto, um constructo democrático constante.

Os recentes resultados dos referendos na França e na Holanda, ${ }^{82}$ dois países fundadores da União Européia, só trazem mais complexidade à questão. Mas, visto por um lado positivo, o "não" serviu para demonstrar que o processo de aprofundamento político na UE não pode ser feito às portas fechadas, de acordo com uma ideologia intergovernamental, mas sim da forma mais aberta e democrática possível.

Enfim, como fala Habermas, em artigo recente sobre a Constituição Européia e os resultados dos referendos Francês e Holandês, "na história, nada de essencial muda sem atos simbólicos, sem signos que as gerações futuras olham em retrospectiva com o fim de obterem um ponto arquimédico para o seu futuro". ${ }^{83}$

\section{Referências}

BARROSO, Luís Roberto. Interpretação e Aplicação da Constituição. 4. ed. Rio de Janeiro: Renovar, 2002.

CANOTILHO, José Joaquim Gomes. Aproximação às Soberanias: Estado, Povo, Cidadão. Tópicos para uma Intervenção no VI Curso de História Contemporânea. Fundação Mário Soares. Disponível em: < http://www.fd.uc.pt/docentes/jjgc/aproximacaoassoberanias.pdf>. Acesso em: 18 maio 2005.

CANOTILHO, José Joaquim Gomes. Direito Constitucional e Teoria da Constituição. Coimbra: Almedina, 2002.

CARVALHO NETO, Menelick de. Reflexões sobre a Relação entre Constituição, Povo e Estado a partir da Discussão de uma Constituição para a Europa. Revista do Instituto de Hermenêutica Jurídica, Porto Alegre, n. 2, 2004.

CATTONI, Marcelo. O Projecto Constituinte de um Estado Democrático de Direito: um Exercício de Patriotismo Constitucional no Marco da Teoria Discursiva do Direito e do Estado

\footnotetext{
82 Antes mesmo dos resultados negativos da França e da Holanda, Jo Shaw já havia escrito um artigo analisando as conseqüências de uma resposta contrária ao referendo de ratificação da Constituição Européia. Cf. SHAW, Jo. What Happens if the Constitional Treaty is not Ratified? European Policy Brief. The Federal Trust for Education and Research. Disponível em: <www.fedtrust.co.uk>. Acesso em: 18 maio 2005.

${ }^{83}$ HABERMAS, 2005.
}

A \& C R. de Dir. Administrativo e Constitucional, Belo Horizonte, ano 6, n. 24, p. 141-162, abr./jun. 2006 
Democrático de Direito de Jürgen Habermas. Texto cedido pelo professor Menelick de Carvalho Neto na disciplina Elementos de Teoria Constitucional do mestrado em Direito da UnB.

CHURCHILL, Winston. Discurso proferido em 19/09/1946 na Universidade de Zurique. Disponível em: < http://www.coe.int/t/pt/com/About_COE/POR_disc_Churchill.asp > . Acesso em: 21 jun. 2005.

CRAIG, P. P. The European Court and National Courts, Doctrine and Jurisprudence: Legal Change in its Social Context. EUI Working Paper RSC, Florence, n. 95/29.

DUARTE, Fernanda; VIEIRA, José Ribas (Org.). Teoria da Mudança Constitucional: sua Trajetória nos Estados Unidos e na Europa. Rio de Janeiro: Renovar, 2005.

ERIKSEN, Erik Oddvar. Why a Charter of Fundamental Human Rights in the EU? ARENA Working Papers. WP 02/36. Disponível em: < http://www.arena.uio.no/publications/workingpapers2002/papers/wp02_36.htm>. Acesso em: 18 maio 2005.

FRANCA FILHO, Marcílio Toscano. De Paris a Amsterdam. Os Caminhos da Experiência Comunitária Européia. Revista de Informação Legislativa, n. 144, out./dez. 1999.

FRANCA FILHO, Marcílio Toscano. Introdução ao Direito Comunitário. São Paulo: Juarez de Oliveira, 2002.

GARCÍA, Fernando Silva. La Unión Europea. Problemas Constitucionales Derivados de su Estructura y Funcionamiento Institucional. Boletín Mexicano de Derecho Comparado, n. $104,2002$.

GRIMM, Dieter. Does Europe need a Constitution. European Law Journal, n. 3, nov. 1995.

HABERLE, Peter. El Estado Constitucional Europeo. Revista Mexicana de Derecho Constitucional, n. 2, 2000.

HABERLE, Peter. Europa como Comunidade Constitucional en Desarollo. Revista de Derecho Constitucional Europeo, n. 1, jan.-jun. 2004.

HABERMAS, Jürgen. A Constelação Pós-nacional: Ensaios Políticos. Tradução de Márcio Seligmann-Silva. São Paulo: Littera Mundi, 2001.

HABERMAS, Jürgen. A Europa Necessita de uma Constituição? Um Comentário sobre Dieter Grimm. In: A Inclusão do Outro. Tradução George Sperber, Paulo Astor Soethe e Milton Camargo Mota. 2. ed. São Paulo: Loyola, 2004.

HABERMAS, Jürgen. A Imaginação contra o Poder. Folha de S.Paulo, 12 jun. 2005.

HABERMAS, Jürgen. Por qué la Unión Europea Necesita un Marco Constitucional? Boletín Mexicano de Derecho Comparado, n. 105, set.-dez. 2002.

HOBSBAWM, Eric. Era dos Extremos: o breve Século XX: 1914-1991. Tradução Marco Santarrita. 2. ed. São Paulo: Companhia das Letras, 2002.

JOERGES, C.; MÉNY, Y.; WEILER, J. H. H. What Kind of Constitution for what Kind of Polity? Responses to Joschka Fischer. Florencia: European Universitary Institute, 2000. Disponível também no site do Jean Monnet Programm: < http://www.jeanmonnetprogram. org/papers/00/symp.html>. Acesso em: 18 maio 2005.

KLABBERS, Jan; LEINO, Päivi. Death by Constitution: the Draft Treaty Stablishing a Constitution for Europe. German Law Journal, n. 12, 2003. Disponível em: <www. 
germanlawjournal.com>. Acesso em: 18 maio 2005.

LUCAS, Javier de. Perplejidades ante la Constitución Europea. Jueces para la Democracia. Información y Debate, n. 50, 07/2004. Disponível em: <www.juecesdemocracia.es/publicaciones/ revista/articulosinteres/lucas.pdf>. Acesso em: 18 maio 2005.

LUQUE, Luis Aguiar de. Os Direitos Fundamentais no Processo de Integração Européia. In: HOFMEISTER, Wilhelm (Org.). Anuário Brasil-Europa: Direitos Humanos e Relações Externas. Rio de Janeiro: Konrad-Adenauer-Stiftung, 2004.

MALLÉN, Beatriz Tomás. A Carta dos Direitos Fundamentais da União Européia ou a Otimização da Proteção dos Direitos e Liberdades na Europa. In: HOFMEISTER, Wilhelm (Org.). Anuário Brasil-Europa: Direitos Humanos e Relações Externas. Rio de Janeiro: Konrad-Adenauer-Stiftung, 2004.

PAGLIARINI, Alexandre Coutinho. A Constituição Européia como Signo: da Superação dos Dogmas do Estado Nacional. Rio de Janeiro: Lumen Juris, 2005.

PERNICE, Ingolf. European v. National Constitutions. European Constitutional Law Review, n. 1,2005 .

PERNICE, Ingolf. Multilevel Constitutionalism and the Treaty of Amsterdam: European Constitution-making Revisited. Common Market Law Review, 36, 1999.

PFETSCH, Frank R. A União Européia: História, Instituições, Processos. Tradução de Estevão C. de Rezende Martins. Brasília: Ed. UnB, 2001.

PUIG, Gonzalo Villalta. The European Constitution: Past and Future. Technical Report NEC Paper, n. 115, National Europe Centre, ANU, 2003. Disponível em: < http://eprints.anu. edu.au/archive/00003054/01/Puig_Constitution.pdf>. Acesso em: 18 maio 2005.

ROSEnfELD, Michel. A Identidade do Sujeito Constitucional. Tradução de Menelick de Carvalho Neto. Belo Horizonte: Mandamentos, 2003.

ROSENFELD, Michel. The Rule of Law and the Legitimacy of Constitutional Democracy. Working Paper Series, New York, n. 36, mar. 2001.

SÁNCHEZ, Miguel Azpitarte. Las Relaciones entre el Derecho de la Unión y el Derecho del Estado a la Luz de la Constitución Europea. ReDCE, n. 1, 2004.

SCHUTTER, Olivier de. The Implementation of the EU Charter of Fundamental Rights Through the Open Method of Coordination. Jean Monnet Working Papers, n. 7, 2004. Disponível em: < http://www.jeanmonnetprogram.org/papers/04/04071.pdf>. Acesso em: 18 maio 2005.

SHAW, Jo. What Happens if the Constitional Treaty is not Ratified? European policy brief. The Federal Trust for Education and Research. Disponível em: <www.fedtrust.co.uk>. Acesso em: 18 maio 2005.

TOSTES, Ana Paula. A Supranacionalidade e a Democracia: o Caso Europeu. Revista Contexto Internacional, v. 23, 2001.

VIERA, José Ribas (Org.). A Constituição Européia: o Projeto de uma Nova Teoria Constitucional. Rio de Janeiro: Renovar, 2004.

VILLA, Francisco Javier Donaire. Constituições Nacionais e Integração Européia. In: HOFMEISTER, Wilhelm (Org.). Anuário Brasil-Europa: Direitos Humanos e Relações Externas. Rio de Janeiro: Konrad-Adenauer-Stiftung, 2004.

A \& C R. de Dir. Administrativo e Constitucional, Belo Horizonte, ano 6, n. 24, p. 141-162, abr.jun. 2006 
VILlalón, Pedro Cruz. La Constitución Inédita: Estúdios ante la Constitucionalización de Europa. Madrid: Ed. Trotta, 2004.

WEILER, Joseph H.H. Der Staat “über alles”Demos, Telos and the German Maastricht decision. Harvard Jean Monnet Working Paper, n. 6, 1995. Disponível em < http://www. jeanmonnetprogram.org/papers/95/9506ind.html>. Acesso em: 18 maio 2005.

WEINER, Antje. Evolving Norms of Constitutionalism in Europe: From Treaty Language to Constitution. In: WEILER; EISGRUBER (Org.). Altneuland: The EU Constitution in a Contextual Perspective. Jean Monnet Working Paper, 5/04. Disponível em: < http://www. jeanmonnetprogram.org/papers/04/040501-06.html>. Acesso em: 18 maio 2005.

WITTE, Bruno de. The National Dimension of European Treaty revision: Evolution and Recent Debates. Florence: European University Institute, 2004.

Informação bibliográfica deste texto, conforme a NBR 6023:2002 da Associação Brasileira de Normas Técnicas (ABNT):

MARQUES, Raphael Peixoto de Paula. Dilemas do constitucionalismo contemporâneo: é possível uma Constituição para a União Européia? A\&C Revista de Direito Administrativo e Constitucional, Belo Horizonte, ano 6, n. 24, p. 141-162, abr./jun. 2006. 